\title{
Comparative adsorption of crude oil using mango (Mangnifera indica) shell and mango shell activated carbon
}

\author{
Babatope Abimbola Olufemi ${ }^{\dagger}$, Funmilayo Otolorin \\ Department of Chemical and Petroleum Engineering, University of Lagos, Akoka, Lagos 23401, Nigeria
}

\begin{abstract}
Mango shell (MS) and mango shell activated carbon (MSAC) was used to adsorb crude oil from water at various experimental conditions. The MSAC was prepared by carbonization at $450^{\circ} \mathrm{C}$ and chemical activation using strong $\mathrm{H}_{3} \mathrm{PO}_{4}$ acid. The adsorbents were characterized with Fourier Transform Infrared spectroscopy. Investigations carried out included the effects of parametric variations of different adsorbate dose, adsorbent dose, time, temperature, $\mathrm{pH}$ and mixing speed on the adsorption of crude oil. The equilibrium isotherm for the adsorption process was determined using Langmuir, Freundlich, Temkin and Dubinin Radushkevich isotherm models. Temkin isotherm was found to fit the equilibrium data reasonably well than others. The result demonstrated that MSAC was more effective for crude oil adsorption than raw mango shell. Optimum conditions were also presented. The enhanced effect from activation was justified statistically using Analysis of Variance and Bonferroni-Holm Posthoc significance test. The pseudo first order kinetics gave a better fit for crude oil adsorption with both MS and MSAC.
\end{abstract}

Keywords: Activated carbon, Adsorption, Crude oil, Mango shell, Optimization

\section{Introduction}

Oil spillage posed a global issue that has been occurring since the discovery of crude oil. Oil spill accidents often take place during oil utilization processes, resulting in energy loss as well as threats to the environment [1]. Oil transportation poses a highly risky business and oil spills need swift attention. As a matter of necessity, after an oil spill, marine cleanup operations need to collect or adsorb quickly a major part of any oil spilled [2].

Oil spills could be from human mistakes and carelessness, as well as deliberate acts of vandalism, war, illegal dumping, or by natural disasters such as hurricanes or earthquakes in some cases [3]. Massive marine oil spills have resulted in a great deal of damage to marine habitations. It had also led to economical impacts on fisheries, agriculture, tourism, and loss of energy source. Ayotamuno et al. [4] in 2005 reported that soils soaked with crude oil instantly loses fertility and initiates environmental degradation processes. Also, Broder and Zeller [5] in 2010 came up with the fact that oil spill had resulted in changes of soil $\mathrm{pH}$ which affected solubility and abundance of micro-nutrients. Inland water bodies are also affected by leaking of oil through pipelines, refineries, storage facilities, runoff from oil fields, and in some cases, process effluent from petroleum refineries and petrochemical plants. The methods commonly used to remove spill involve oil booms, dispersants, skimmers, in situ burning and so on. However, most of them require substantial financial input and their use is restricted because of cost factors, which often overrides the importance of pollution control [6]. Also most of the dispersants are often inflammable and cause health hazards to the operators and potential damage to animal and plant life. It could also lead to fouling of shorelines and contamination of water source.

Adsorption is identified as a cost-effective method to reduce the environmental problems of oil spill and pollution cleanups. The use of sorbent poses one of the most economical and efficient methods for combating oil spills. The accepted sorbent materials are affordable, accessible, have fast oil sorption rate, high oil sorption capacity (exhibits oleophilicity or lipophilicity), low water pickup, high oil retention capacity for transfer, high recovery rate of the adsorbed oil with easy methods, sound reusability, as well as high buoyancy properties.

Three major classes of oil sorbents, include organic synthetic products, inorganic mineral products, and organic natural products. Majority of the commercially available oil sorbents are organic synthetic products such as polypropylene (PP) and polyurethane materials.
This is an Open Access article distributed under the terms of the Creative Commons Attribution Non-Commercial License (http://creativecommons.org/licenses/by-nc/3.0/) which permits unrestricted non-commercial use, distribution, and reproduction in any medium, provided the original work is properly cited.
Received January 23, 2017 Accepted May 19, 2017

${ }^{\dagger}$ Corresponding author

Email: bolufemi@yahoo.com

Tel: +234-8023162183

Copyright (C) 2017 Korean Society of Environmental Engineers 
Some of the mineral products used as oil sorbents include perlite, exfoliated graphite, vermiculites, organoclay, and zeolite to mention a few. Most of them usually have poor buoyancy and oil sorption capacity in the field. They could also be difficult to handle on site due to their granular or powder forms [1]. Most of them also exhibit poor oil recovery and reusability. As a result of their low hydrophobicity, they may also experience collapse of their microstructure due to water sorption. Exfoliated graphite and silica gel seems to be excellent oil sorbents, but they are fairly expensive. These limitations have led to the recent interest in seeking alternative materials, especially biodegradable natural agro-based products.

An agricultural solid waste seems cheap, abundant, and easily available. Over the years, some researchers have focused on the feasibility of the low-cost materials that were derived from agro-wastes for oil and heavy metals removal [7]. Effective usage of these waste materials enhances their reuse and savings in disposal fee. As a supportive means of enhancing the quality of this present work, previous contributions in the field of adsorption and waste water treatments were acknowledged [8-23].

In this research, mango shell (MS) and mango shell activated carbon (MSAC) were used as the adsorbent, without the edible part of the peel or fibrous material. The seeds are within the nuts, and are not the consumable part of mango, usually discarded as wastes. Activated carbon prepared from MS has been applied for colour adsorption and removal of heavy metals from waste water due to its well developed pore volume and large surface area [24]. Some researchers have converted mango seed into activated carbon [25], but more investigation into the usage of MS and MSAC in adsorbing crude oil seems relatively few to other reported agro wastes.

The objective of this study is therefore on the possibility of using an agro-waste like MS and MSAC to adsorb crude oil, investigating various relevant physical parameters as they influence the adsorption process. The usage of Langmuir, Freundlich, Temkin and Dubinin Radushkrvich isotherm models is employed to evaluate the sorption capacity of the adsorbents as well as to determine the kinetics and optimum parameters under which adsorption of crude oil with the two adsorbents are most effective. Statistical application of Analysis of Variance (ANOVA) and Bonferroni-Holm Posthoc significance test to justify the adsorption operation is also examined. The outcome of the research is expected to propose MS and MSAC as useful materials for environmental control of crude oil spills.

\section{Materials and Methods}

\subsection{Apparatus and Reagent}

The following materials and apparatus were utilized for the experimental work:

England Pyrex beakers (50-500 mL), England Pyrex conical flasks (50-500 mL), England Pyrex measuring cylinders (50-1,000 mL), England Surgifield Model SM 1002A Muffle electric furnace, Parsippany, New Jersey, United States OHAUS Model P4102 Electronic Mass Balance, Germany Merck KGaA Whatman (Model 1001-125) 125 mm diameter filter paper, England Mesh Sieve (Model
BSS 410/43), Lemfield Medical England Model DHG9053A Heating Drying Oven, United States Hanna Instruments model HI98107 pH meter, spatula, United States The Lab Depot Inc. Model RS232 orbital shaker, Australia RATEK model SWB20D water bath shaker, United Kingdom Jenway Model 6405 Ultraviolet (UV) spectrophotometer, de-ionized water, Nigerian Niger Delta Bonny Light crude oil, MS, $85 \% \mathrm{w} / \mathrm{w}$ ortho-phosphoric acid and United States PerkinElmer Fourier Transform Infrared (FTIR) Spectrophotometer Spectrum 2000 Model.

\subsection{Preparation of Simulated oil Spill}

A typical small oil spill of $0.025 \mathrm{~g} / \mathrm{L}$ initial concentration was simulated by pouring $25 \mathrm{~g}$ of crude oil into $1,000 \mathrm{~mL}$ of distilled water in a beaker.

\subsection{Preparation of Adsorbent}

The mango nuts collected were washed and dried in the sun at room temperature for one week and cracked using hammer, the shell was then removed and dried under sun light at room temperature for two weeks. The shell was oven-dried at $105^{\circ} \mathrm{C}$ after which they were crushed using laboratory mortar and pestle. The particles were sieved with $80 \mu \mathrm{m}$ sieve size. Some part was stored in a plastic bottle for experimentation. Some other sieved samples were impregnated in $\mathrm{H}_{3} \mathrm{PO}_{4}$ at impregnation ratio of 1:1 by measuring $100 \mathrm{~g}$ of sample in $100 \mathrm{~mL}$ of reagent. The impregnated sample was left at room temperature for $24 \mathrm{~h}$. After impregnation, the excess solution was filtered off. Finally the resulting sample was carbonized in a heated furnace at a temperature of $450^{\circ} \mathrm{C}$ for 30 min. The activated carbon was rinsed with distilled water and dried at $105^{\circ} \mathrm{C}$ for $1 \mathrm{~h}$ in the furnace. Finally the activated carbon produced was kept in a tightly closed plastic bottle.

\subsection{Characterization of Adsorbent}

FTIR spectroscopic analysis was performed on the MS and MSAC using FTIR spectroscope (FTIR-2000, Perkin-Elmer) to determine the functional groups present. The spectra were measured from below 400 to $5,000 \mathrm{~cm}^{-1}$.

\subsection{Batch Adsorption Equilibrium Studies}

Exactly $100 \mathrm{~mL}$ of the simulated oil spill of initial concentration of $0.025 \mathrm{~g} / \mathrm{L}\left(\mathrm{C}_{\mathrm{O}}\right)$ was used for each study. The equilibrium concentration of crude oil in water for each measured sample was determined using UV spectrophotometer. The weight $(\mathrm{m})$ of the adsorbents, volume (V) of simulated oil spill and the corresponding equilibrium concentration $\left(\mathrm{C}_{\mathrm{e}}\right)$ were recorded. For each batch run, the quantity of crude oil adsorbed per unit weight of adsorbent denoted as $q_{e}$ was determined with Eq. (1) expressed by Uzoije et al. [26] as:

$$
q_{e}=\frac{V(C o-C e)}{m}
$$

The percent removal is expressed in Eq. (2) as:

$$
\% \text { Removal }=\frac{100\left(C o-C_{e}\right)}{C o}
$$


The mean values were calculated and utilized after double runs for reproducibility errors.

\subsubsection{Effect of adsorbent dose}

About $0.025 \mathrm{~g} / \mathrm{L}$ initial concentration oil sample was added to mixtures of $1.0 \mathrm{~g}, 2.0 \mathrm{~g}, 3.0 \mathrm{~g}, 4.0 \mathrm{~g}$ and $5.0 \mathrm{~g}$ of $80 \mu \mathrm{m}$ MSAC, respectively in a $500 \mathrm{~mL}$ beaker. The beaker was placed on an orbital stirrer, and then stirred at $200 \mathrm{rpm}$ at temperature of $25^{\circ} \mathrm{C}$ for an hour each. The absorbance values was recorded carefully during the experiments, this was also repeated for the raw mango sample.

\subsubsection{Effect of contact time}

About $0.025 \mathrm{~g} / \mathrm{L}$ initial concentration oil sample was added to a mixture of $2.0 \mathrm{~g}$ of $80 \mu \mathrm{m}$ MSAC in a $500 \mathrm{~mL}$ beaker. The beaker was placed on an orbital stirrer, and then stirred at $200 \mathrm{rpm}$ for various contact time: 15, 30, 45, 60, and $75 \mathrm{~min}$. After stirring, the samples were withdrawn at the specified time intervals, filtered through a filter paper and the filtrate measured using a UV machine. The absorbance values were then recorded; this was also repeated for the raw mango sample.

\subsubsection{Effect of temperature}

Batch adsorption experiments were carried out at different temperatures of $15,25,35,45$ and $60^{\circ} \mathrm{C}$. About $2.0 \mathrm{~g}$ of the MSAC was shaken with $0.025 \mathrm{~g} / \mathrm{L}$ initial concentration oil sample in a 500 $\mathrm{mL}$ beaker at $200 \mathrm{rpm}$ for $1 \mathrm{~h}$ at various temperatures. The wetted adsorbent was then removed from the beaker, while the oil and water filtered through a filter paper and the filtrate measured using a UV spectrophotometer. The absorbance values were obtained and recorded. This was also done for ordinary mango samples.

\subsubsection{Effect of $\mathrm{pH}$}

The effect of $\mathrm{pH}$ on crude oil adsorption was studied by agitating $2 \mathrm{~g}$ of the activated carbon in a $200 \mathrm{~mL}$ of the prepared samples with concentration of $0.025 \mathrm{mg} / \mathrm{L}$ at different $\mathrm{pH}$ values, which ranged from 5-9. The samples were agitated for $1 \mathrm{~h}$ to reach equilibrium and agitation speed was maintained at $200 \mathrm{rpm}$. The $\mathrm{pH}$ of the solution was adjusted to the desired value by drop wise addition of $0.1 \mathrm{M}$ hydrochloric acid ( $\mathrm{HCl})$ and $0.1 \mathrm{M}$ sodium hydroxide $(\mathrm{NaOH})$. After removing the adsorbent, the oil and water were filtered through a filter paper and the filtrate measured using a UV spectrophotometer. The absorbance values were recorded. This was also repeated for ordinary mango samples.

\subsubsection{Effect of adsorbate dose}

Batch adsorption experiments was carried out at different adsorbate dose in which $2.0 \mathrm{~g}$ of MSAC was shaken with 2, 4, 6, 8, and $10 \mathrm{~g}$ crude oil samples per $200 \mathrm{~mL}$ water mix in a $500 \mathrm{~mL}$ beaker to give varying oil concentrations at $200 \mathrm{rpm}$ for $60 \mathrm{~min}$ using constant ambient temperature. The wetted adsorbent was then removed from the beaker, while the oil and water were filtered through a filter paper and the filtrate measured using a UV machine. The absorbance values were then taken. This was repeated for raw mango samples.

\subsubsection{Effect of rotational speed}

Batch experiment was carried out by adding $0.025 \mathrm{~g} / \mathrm{L}$ initial concen- tration oil sample to a $2.0 \mathrm{~g} 80 \mu \mathrm{m}$ corncobs adsorbent in a 500 $\mathrm{mL}$ beaker. The beaker was placed on an orbital stirrer, and then stirred at constant room temperature for a specified revolution per minute for $60 \mathrm{~min}$. Various rotational speeds of 100, 200, 300, 400 and $500 \mathrm{rpm}$ were used. After stirring, the samples were withdrawn at the specified time intervals, filtered through a filter paper and the filtrate were measured using a UV machine. The absorbance values were recorded. The procedure was repeated for raw mango samples.

\section{Results and Discussion}

\subsection{Physical Properties of Adsorbents}

Some physical properties of the adsorbents were determined. Typical average values of the percent moisture content, bulk density, specific gravity and porosity were $1.2 \%, 0.42 \mathrm{~g} / \mathrm{mL}, 0.57$ and 0.69 for MS, while $1.8 \%, 0.40 \mathrm{~g} / \mathrm{mL}, 0.70$ and 0.92 were obtained for MSAC, respectively.

\subsection{Fourier Infra-Red Spectroscopy Images of Adsorbents}

Fourier Infra-Red spectroscopy conducted on the MS and MSAC revealed the presence of many peaks indicating different functional groups as presented in Fig. 1 to 4 below, which make the adsorbents viable for adsorption. All assignments were made and observed in accordance with Coates [27]. The heavier functional groups could be identified at the smaller wave numbers, while the lighter aliphatic bonds sited at the larger wave numbers.

The FTIR analysis revealed the presence of many peaks indicating various functional groups within the adsorption operation. The spectrum of the MS before and after adsorption showed the broad and intense peak between $2,851 \mathrm{~cm}^{-1}$ and 2,953 $\mathrm{cm}^{-1}$ which was attributed to the stretching of C-H group due to alkyl bond. The peak also observed at $1,242.99 \mathrm{~cm}^{-1}$ was associated with stretching vibration of C-O group due to carboxylic acid. The peak around $1,500 \mathrm{~cm}^{-1}$ corresponded to the C-C stretching which might be attributed to aromatic bond.

The FTIR spectrum of MSAC before and after adsorption showed the peak between $2,840.20 \mathrm{~cm}^{-1}$ and $2,901.04 \mathrm{~cm}^{-1}$ was attributed to the stretching of $\mathrm{C}-\mathrm{H}$ group due to alkyl bond, and that observed at $1,451 \mathrm{~cm}^{-1}$ was due to $\mathrm{C}-\mathrm{C}$ stretching which might be attributed to aromatic bond.

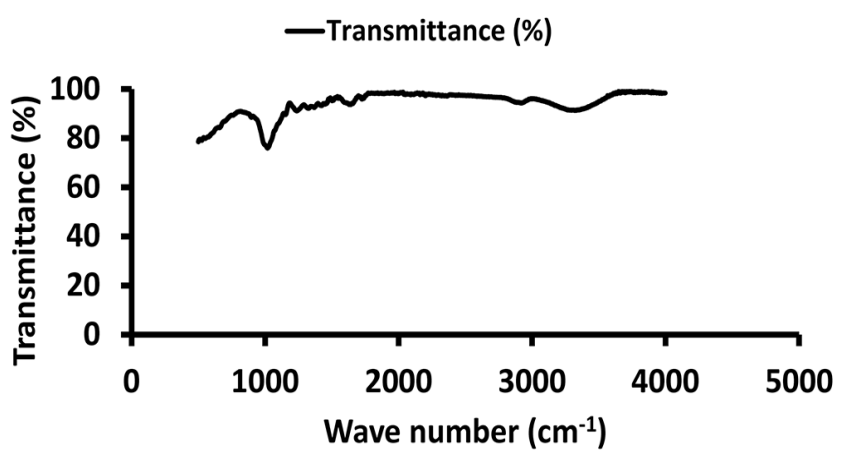

Fig. 1. FTIR analysis of MS before adsorption. 


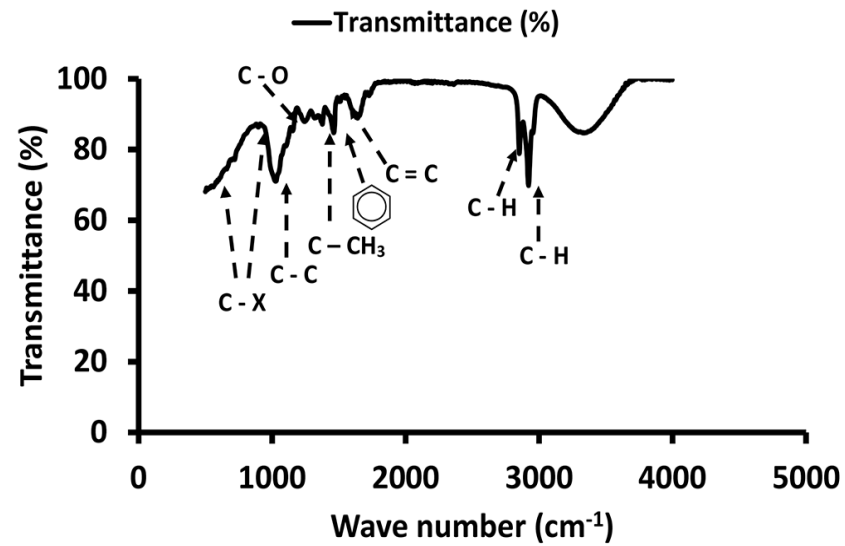

Fig. 2. FTIR analysis after adsorption for removal of crude oil using $2.0 \mathrm{~g}$ of $80 \mu \mathrm{m} \mathrm{MS}$ at $0.025 \mathrm{~g} / \mathrm{L}$ initial oil concentration, $\mathrm{pH}$ of $7.0,25^{\circ} \mathrm{C}$ temperature, $200 \mathrm{rpm}$ and one hour.

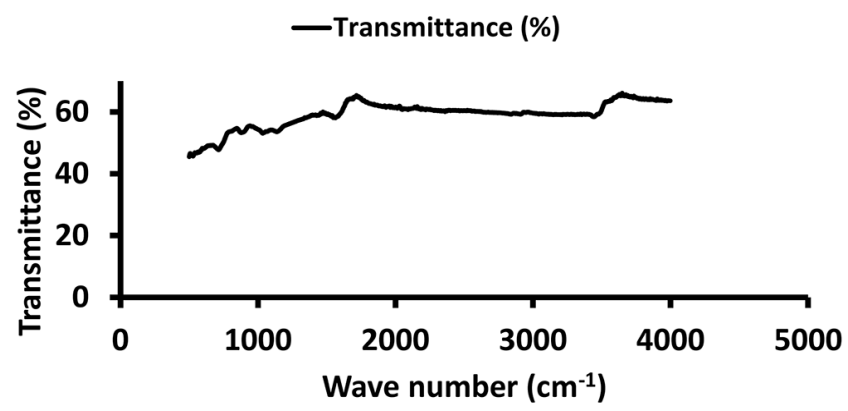

Fig. 3. FTIR analysis of MSAC before adsorption.

-Transmittance (\%)

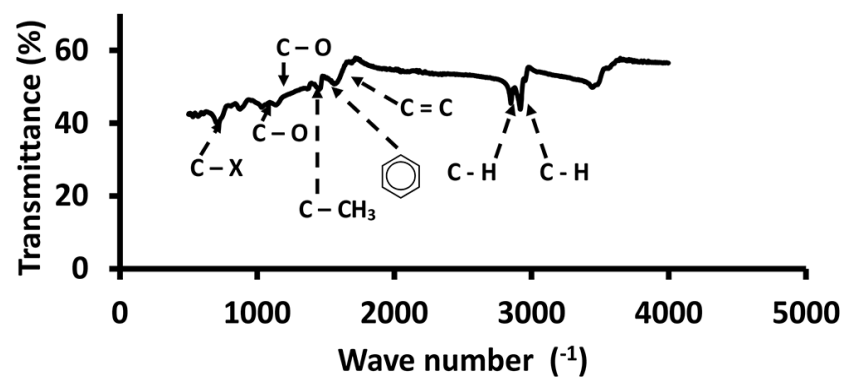

Fig. 4. FTIR analysis after adsorption for removal of crude oil using $2.0 \mathrm{~g}$ of $80 \mu \mathrm{m} \mathrm{MSAC}$ at $0.025 \mathrm{~g} / \mathrm{L}$ initial oil concentration, $\mathrm{pH}$ of $7.0,25^{\circ} \mathrm{C}$ temperature, $200 \mathrm{rpm}$ and one hour.

This showed that the adsorption process caused the peak fall in transmittance which indicated that some functional groups were present.

\subsection{Batch Adsorption Equilibrium Studies Results}

\subsubsection{Effect of adsorbent dose}

It was observed from Fig. 5(a) that as the adsorbent increased from 1 to $5 \mathrm{~g}$, the percentage removal increased. The increase in the adsorption percentage with increase in dose of adsorbent was due to the increase in active sites of the adsorbent and thus making easier penetration of the crude oil molecules into the adsorption sites. Similar experience was observed by Itodo and Itodo [28].

\subsubsection{Effect of contact time}

The extent of crude oil removal by the two adsorbents was found to increase as the contact time increased from 15 to $75 \mathrm{~min}$ as shown in Fig. 5(b). The adsorption of crude oil using the adsorbents was found to be rapid initially and then become slower with the increase of contact time. This may be due to the reducing strong attractive forces between the crude oil molecules and the adsorbent as contact time increased especially after sometime between 60 to $75 \mathrm{~min}$. It gradually approached almost constant value at equilibrium. The percentage removal of MSAC was higher than that of the inactivated MS which also showed that more active sites were available in the MSAC.

\subsubsection{Effect of temperature}

The batch adsorption experiments result carried out for different temperatures of adsorbent shown in Fig. 5(c) indicated that adsorption capacity was higher at lower temperatures. The percentage removal was high at $15^{\circ} \mathrm{C}$ for the temperature range considered. The results further showed that the percentage removal of the crude oil decreased with increase in temperature, indicating the dependence of adsorption on temperature similarly observed by Bello and Ahmad [29]. The percentage removal of the MSAC was also higher compared to that of the ordinary MS which showed that the MSAC possessed more energy required for adsorption.

\subsubsection{Effect of mixing speed}

The batch adsorption experiment result at different mixing speed as shown in Fig. 5(d) revealed that the adsorption of crude oil onto the adsorbents increased with speed. Lin and Liu [30] reported that mass transfer rate increases with increase in stirring speed. The increase in stirring speed resulted in a reduction in surface film resistance, thereby allowing residual oil to reach the particle surface more easily. Surface film resistance hinders rate of adsorption. The result showed that the rate of adsorption with oil removal gradually increased with speed and the most remarkable adsorption occurred at about $500 \mathrm{rpm}$ similar to the work of Olufemi et al. [31].

\subsubsection{Effect of $\mathrm{pH}$}

Surface charges on the adsorbent and degree of ionization of the adsorbate could be influenced by the $\mathrm{pH}$ of the solution, which makes $\mathrm{pH}$ an important factor in adsorptive studies. The batch experiment result shown in Fig. 5(e) indicated that varying the $\mathrm{pH}$ using the presence of either $\mathrm{OH}^{-}$or $\mathrm{H}^{+}$ions compete with molecules of crude oil for adsorption site. The higher or lower the $\mathrm{pH}$, the higher the concentration of either ion and thus the affects uptake of crude oil molecules. For both adsorbents the neutral $\mathrm{pH}$ seems to be more favourable.

\subsubsection{Effect of adsorbate concentration}

The effect of adsorbate concentration is shown in Fig. 5(f) which revealed that adsorption of crude oil decreased with increase in adsorbate concentration for both adsorbents. Basically this can be explained in terms of available active sites. At low adsorbate 


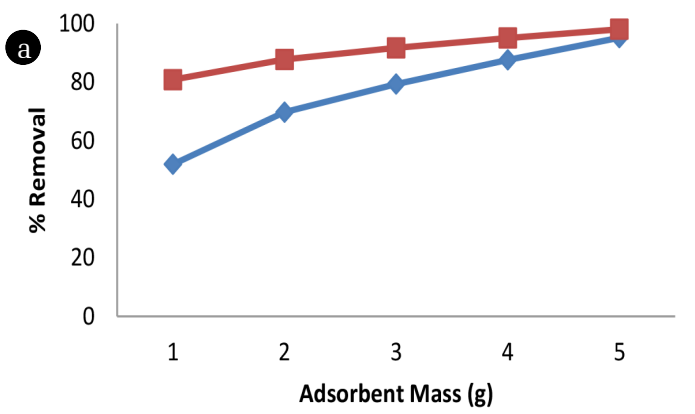

b
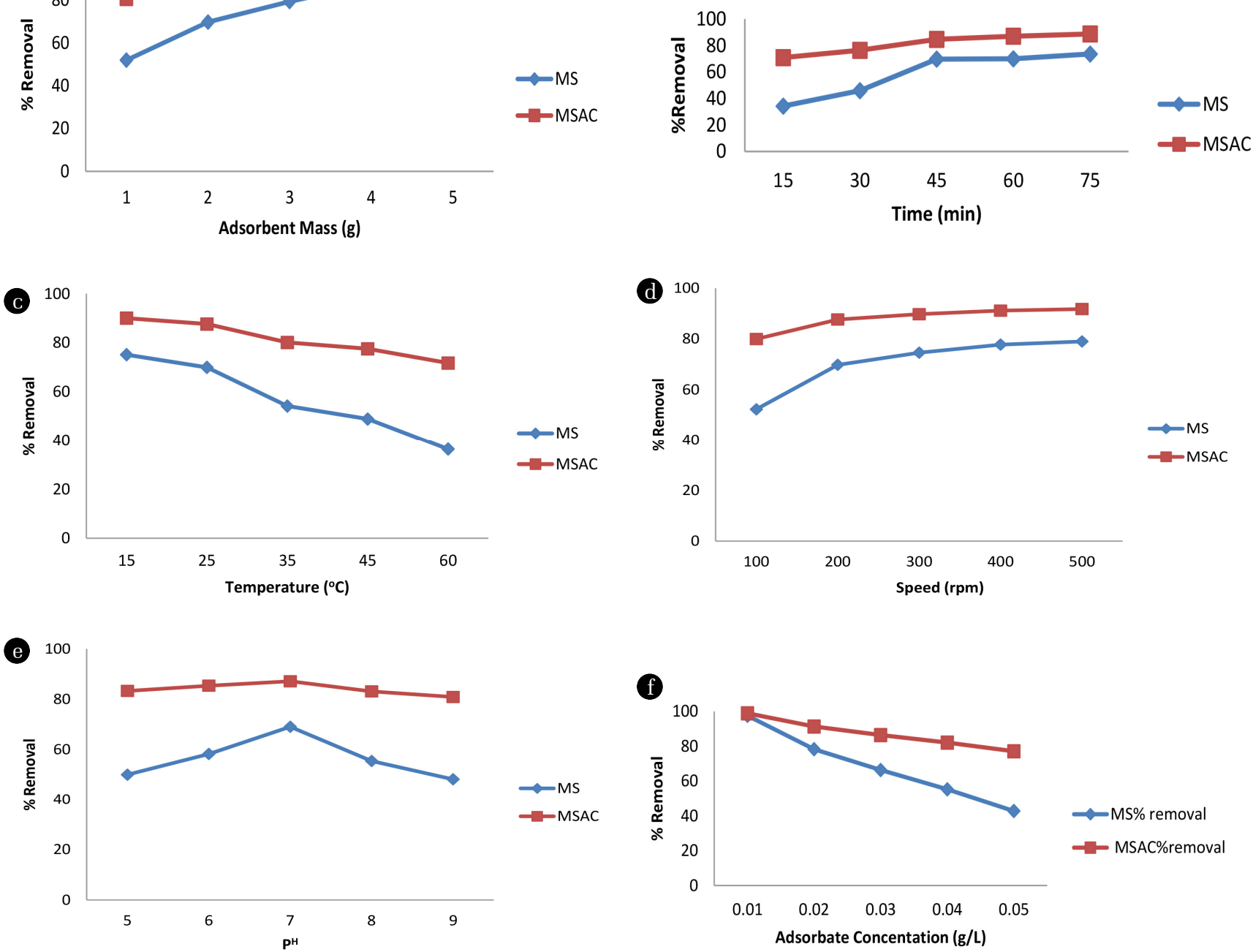

Fig. 5. (a) The effect of adsorbent dose on the \% removal of crude oil using $80 \mu \mathrm{m} \mathrm{MS}$ and MSAC at $0.025 \mathrm{~g} / \mathrm{L}$ initial oil concentration, $\mathrm{pH}$ of $7.0,200 \mathrm{rpm}$ and $25^{\circ} \mathrm{C}$ for one hour each. (b) The effect of contact time on the \% removal of crude oil using $2.0 \mathrm{~g}$ of 80 $\mu \mathrm{m}$ MS and MSAC at $0.025 \mathrm{~g} / \mathrm{L}$ initial oil concentration, $\mathrm{pH}$ of $7.0,200 \mathrm{rpm}$ speed, and $25^{\circ} \mathrm{C}$ temperature. (c) The effect of temperature on the \% removal of crude oil using $2.0 \mathrm{~g}$ of $80 \mu \mathrm{m} \mathrm{MS}$ and MSAC at $0.025 \mathrm{~g} / \mathrm{L}$ initial oil concentration, pH of 7.0, $200 \mathrm{rpm}$ speed, and one hour each. (d) The effect of mixing speed on the \% removal of crude oil using $2.0 \mathrm{~g}$ of $80 \mu \mathrm{m} \mathrm{MS}$ and MSAC at $0.025 \mathrm{~g} / \mathrm{L}$ initial oil concentration, $\mathrm{pH}$ of $7.0,25^{\circ} \mathrm{C}$ temperature and one hour each. (e) The effect of $\mathrm{pH}$ on the \% removal of crude oil using $2.0 \mathrm{~g}$ of $80 \mu \mathrm{m} \mathrm{MS}$ and MSAC at $0.025 \mathrm{~g} / \mathrm{L}$ initial oil concentration, $200 \mathrm{rpm}$ speed, $25^{\circ} \mathrm{C}$ temperature and one hour each. (f) The effect of adsorbate concentration on \% removal of crude oil using $2.0 \mathrm{~g}$ of $80 \mu \mathrm{m} \mathrm{MS}$ and MSAC at $200 \mathrm{rpm} \mathrm{speed,} \mathrm{pH}$ of $7.0,25^{\circ} \mathrm{C}$ temperature and one hour each.

concentration, the ratio of surface active sites to crude oil was high. Hence the crude oil interacted with the sorbent to occupy the active sites on the carbon surface sufficiently, and was removed from the solution as observed in some adsorption processes [32, 33], but with the increase in adsorbate concentration, the number of active adsorption sites was not enough to accommodate crude oil molecules.

\subsection{Adsorption Isotherms}

The Freundlich, Langmuir, Temkin and Dubinin-Radushkevich isotherms were used to investigate sorption processes. They are expressed in Eq. (3) to Eq. (6) as follows:

A linear form of the Freundlich expression is:

$$
\ln q_{e}=\ln K_{f}+\frac{1}{n} \ln C_{e}
$$

The Langmuir Isotherm is given as:

$$
\frac{1}{q_{e}}=\frac{1}{q_{m}}+\frac{1}{q_{m} K_{L} C_{e}}
$$


Table 1. Various Adsorption Isotherm Constants for MS and MSAC using Different Operating Parameters

\begin{tabular}{|c|c|c|c|c|c|c|c|c|c|c|c|c|}
\hline \multicolumn{13}{|c|}{ MS } \\
\hline \multirow[b]{2}{*}{ Varied Parameter } & \multicolumn{3}{|c|}{ Freundlich constants } & \multicolumn{3}{|c|}{ Langmuir constants } & \multicolumn{3}{|c|}{ Temkin constants } & \multicolumn{3}{|c|}{ Dubinin constants } \\
\hline & $\mathbf{K}_{\mathrm{f}}$ & $\mathbf{n}$ & $\mathbf{R}^{2}$ & $\mathbf{q}_{\mathrm{m}}$ & $\mathbf{K}_{\mathrm{L}}$ & $\mathbf{R}^{2}$ & $\mathbf{b}_{\mathrm{T}}$ & $\mathbf{A}_{\mathrm{T}}$ & $\mathbf{R}^{2}$ & $\mathbf{q}_{\mathbf{D}}$ & $\mathbf{B}_{\mathbf{D}}$ & $\mathbf{R}^{2}$ \\
\hline Adsorbate Concentration (g/L) & 1.246 & 4.537 & 0.976 & 2.001 & 3.655 & 0.93 & 0.073 & 4.5777 & 0.958 & 1.9687 & 0.0457 & 0.853 \\
\hline Adsorbent Mass (g) & 1.304 & 2.364 & 0.867 & 1.989 & 1.49 & 0.719 & 0.054 & 0.8374 & 0.774 & 1.736 & 0.3063 & 0.492 \\
\hline Contact Time (min) & 3.567 & 1.046 & 0.411 & 1.62 & 0.1612 & 0.648 & 0.048 & 2.048 & 0.746 & 1.555 & 0.7303 & 0.327 \\
\hline Temperature $\left({ }^{\circ} \mathrm{C}\right)$ & 5.646 & 1.688 & 0.992 & 0.785 & 0.2552 & 0.811 & 0.035 & 3.73 & 0.984 & 1.01 & 5.292 & 0.945 \\
\hline Speed (rpm) & 4.692 & 1.969 & 0.976 & 1.068 & 3.914 & 0.906 & 0.043 & 1.66 & 0.988 & 5.477 & 2.695 & 0.875 \\
\hline $\mathrm{pH}$ & 7.137 & 1.455 & 0.982 & 0.865 & 0.252 & 0.934 & 0.035 & 1.01 & 0.994 & 1.024 & 5.9601 & 0.933 \\
\hline \multicolumn{13}{|c|}{ MSAC } \\
\hline \multirow{2}{*}{ Parameter } & \multicolumn{3}{|c|}{ Freundlich constants } & \multicolumn{3}{|c|}{ Langmuir constants } & \multicolumn{3}{|c|}{ Temkin constants } & \multicolumn{3}{|c|}{ Dubinin constants } \\
\hline & $\mathbf{K}_{\mathbf{f}}$ & $\mathbf{n}$ & $\mathbf{R}^{2}$ & $\mathbf{q}_{\mathrm{m}}$ & $\mathbf{K}_{\mathrm{L}}$ & $\mathbf{R}^{2}$ & $\mathbf{b}_{\mathrm{T}}$ & $\mathbf{A}_{\mathbf{T}}$ & $\mathbf{R}^{2}$ & $\mathbf{q}_{\mathbf{D}}$ & $\mathbf{B}_{\mathbf{D}}$ & $\mathbf{R}^{2}$ \\
\hline Adsorbate Concentration (g/L) & 1.789 & 3.494 & 0.974 & 2.82 & 5.184 & 0.898 & 0.062 & 3.543 & 0.884 & 2.828 & 0.0309 & 0.756 \\
\hline Adsorbent Mass (g) & 1.2319 & 1.702 & 0.851 & 2.709 & 1.0458 & 0.749 & 0.03 & 1.0944 & 0.708 & 2.348 & 0.1314 & 0.524 \\
\hline Contact Time (min) & 3.567 & 1.046 & 0.984 & 1.62 & 0.1612 & 0.938 & 0.047 & 2.048 & 0.988 & 1.555 & 0.7303 & 0.909 \\
\hline Temperature $\left({ }^{\circ} \mathrm{C}\right)$ & 4.768 & 0.985 & 0.971 & 1.686 & 1.497 & 0.902 & 0.083 & 2.715 & 0.708 & 1.4734 & 0.3876 & 0.885 \\
\hline Speed (rpm) & 2.679 & 6.455 & 0.985 & 1.859 & 2.45 & 0.94 & 0.107 & 7.618 & 0.988 & 2.07 & 0.1451 & 0.669 \\
\hline $\mathrm{pH}$ & 1.2 & 1.006 & 0.987 & 1.785 & 1.709 & 0.973 & 0.092 & 6.85 & 0.989 & 1.898 & 0.3143 & 0.969 \\
\hline
\end{tabular}

The linearized Temkin Isotherm is expressed as:

$$
q_{e}=\frac{R T}{b_{T}} \ln A_{T}+\frac{R T}{b_{T}} \ln \mathrm{C}_{\mathrm{e}}
$$

The linearized Dubinin-Radushkevich Isotherm is expressed as:

$$
\ln q_{e}=\ln q_{D}-B_{D} R^{2} T^{2}\left(\ln \left(1+\frac{1}{C_{e}}\right)\right)^{2}
$$

In Eq. (6), $B_{D}$ is closely related to the free energy of sorption per mole of the sorbate as it moves to the surface of the adsorbent from infinite distance in the solution and $\mathrm{q}_{\mathrm{D}}$ is a constant related to the degree of sorbate sorption by the adsorbent surface.

The values of the isotherms constants under various operating parameters for MS and MSAC are given in Table 1. Comparing the correlation coefficient $\left(\mathrm{R}^{2}\right)$ values after linearizing and plotting the linear straight line relationships for all the isotherms, indicated that the Temkin isotherm favored the two adsorbents better than other isotherms. This confirmed the relative importance of temperature in the energy involved for the sorption processes.

\subsection{Optimization}

A Statistical Design of Experiment MINITAB (C) software was used to predict the optimum values of percentage removal of each parameter on the overall process. A full factorial design of experiment was used, and afterwards percentage removal was calculated. All the parameters were selected as well as factor levels coded as -1 (low), 0 (middle) and 1 (high).The full factorials design gave 54 runs of experiment and the optimum values obtained are given in Table 2 for MS and MSAC.

\begin{tabular}{|c|c|}
\hline \multicolumn{2}{|c|}{ MS } \\
\hline Parameter & Optimum value \\
\hline Adsobate Concentration (g/L) & 0.043 \\
\hline Adsorbent Mass (g) & 3.992 \\
\hline Time (min) & 50.193 \\
\hline Temperature $\left({ }^{\circ} \mathrm{C}\right)$ & 51.198 \\
\hline Speed (rpm) & 313 \\
\hline $\mathrm{pH}$ & 8.4 \\
\hline \multicolumn{2}{|c|}{ MSAC } \\
\hline Parameter & Optimum value \\
\hline Adsobate Concentration (g/L) & 0.035 \\
\hline Adsorbent Mass (g) & 3.185 \\
\hline Time (min) & 45.267 \\
\hline Temperature $\left({ }^{\circ} \mathrm{C}\right)$ & 40.128 \\
\hline Speed (rpm) & 254 \\
\hline $\mathrm{pH}$ & 7.5 \\
\hline
\end{tabular}

Table 2. Optimum Value of Parameters for MS and MSAC Adsorption

\subsection{Statistical Analysis}

The ANOVA and Bonferroni-Holm Posthoc significance test for crude oil adsorption by MS and MSAC with varying parameters are given in Table 3 .

Fisher's $\mathrm{F}$ is a ratio of the variance between groups to the variance within groups and $\mathrm{P}$ is a probability factor that must be less than 0.05 using the $95 \%$ confidence interval in the ANOVA analysis. The degree of freedom between the groups was 1 , while the degree 
Table 3. Analysis of Variance (ANOVA) and Bonferroni-Holm Posthoc Significance Test for Crude Oil Adsorption by MS and MSAC with varying Parameters

\begin{tabular}{|c|c|c|c|c|c|c|c|c|c|c|}
\hline \multicolumn{11}{|c|}{ MS } \\
\hline \multirow{2}{*}{ Group1 } & \multirow{2}{*}{ Group2 } & \multicolumn{6}{|c|}{ Analysis of Variance (ANOVA) Test } & \multicolumn{3}{|c|}{ Bonferroni-Holm Posthoc Significance Test } \\
\hline & & $\mathbf{S}_{\mathrm{SB}}$ & $\mathbf{S}_{\text {Sw }}$ & $\mathbf{D}_{\mathrm{FB}}$ & $\mathbf{D}_{\mathrm{FW}}$ & $\mathbf{F}$ & $\mathbf{P}$ & $\mathbf{P}_{\mathrm{C}}$ & $\mathbf{P}$ & Significant \\
\hline $\mathrm{C}_{\mathrm{A}}$ & $C_{e}$ & 372.6736 & 510.2681 & 1 & 8 & 5.842789 & 0.042034 & 0.05 & 0.042034 & Yes \\
\hline M & $C_{e}$ & 19.69532 & 80.31096 & 1 & 8 & 1.961906 & 0.198883 & 0.05 & 0.198883 & No \\
\hline $\mathrm{t}$ & $C_{e}$ & $3,009.288$ & $2,335.377$ & 1 & 8 & 10.30853 & 0.012411 & 0.05 & 0.012411 & Yes \\
\hline $\mathrm{T}$ & $C_{e}$ & $1,578.541$ & $1,277.797$ & 1 & 8 & 9.882887 & 0.013728 & 0.05 & 0.013728 & Yes \\
\hline $\mathrm{r}$ & $C_{e}$ & $214,142.5$ & $100,029.7$ & 1 & 8 & 17.12632 & 0.003261 & 0.05 & 0.003261 & Yes \\
\hline $\mathrm{pH}$ & $C_{e}$ & 38.9194 & 26.97408 & 1 & 8 & 11.54276 & 0.009396 & 0.05 & 0.009396 & Yes \\
\hline \multicolumn{11}{|c|}{ MSAC } \\
\hline \multirow{2}{*}{ Group1 } & \multirow{2}{*}{ Group2 } & \multicolumn{6}{|c|}{ Analysis of Variance (ANOVA) Test } & \multicolumn{3}{|c|}{ Bonferroni-Holm Posthoc Significance Test } \\
\hline & & $\mathbf{S}_{\mathrm{SB}}$ & $\mathbf{S}_{\mathrm{SW}}$ & $\mathbf{D}_{\mathrm{FB}}$ & $\mathbf{D}_{\mathrm{FW}}$ & $\mathbf{F}$ & $\mathbf{P}$ & $\mathbf{P}_{\mathrm{C}}$ & $\mathbf{P}$ & Significant \\
\hline $\mathrm{C}_{\mathrm{A}}$ & $C_{e}$ & 59.40431 & 81.5493 & 1 & 8 & 5.827573 & 0.042241 & 0.05 & 0.042241 & Yes \\
\hline M & $C_{e}$ & 1.10224 & 21.28452 & 1 & 8 & 0.414288 & 0.537811 & 0.05 & 0.537811 & No \\
\hline $\mathrm{t}$ & $C_{e}$ & $4,082.582$ & $2,265.023$ & 1 & 8 & 14.41957 & 0.005257 & 0.05 & 0.005257 & Yes \\
\hline $\mathrm{T}$ & $C_{e}$ & $2,459.283$ & $1,233.78$ & 1 & 8 & 15.94632 & 0.003987 & 0.05 & 0.003987 & Yes \\
\hline $\mathrm{r}$ & $C_{e}$ & 220,644 & $100,006.1$ & 1 & 8 & 17.65044 & 0.002991 & 0.05 & 0.002991 & Yes \\
\hline $\mathrm{pH}$ & $C_{e}$ & 22.46401 & 11.40999 & 1 & 8 & 15.75042 & 0.004127 & 0.05 & 0.004127 & Yes \\
\hline
\end{tabular}

Table 4. Pseudo First and Second Order Kinetic Constants

\begin{tabular}{|c|c|c|c|c|c|c|}
\hline \multirow{2}{*}{ Adsorbent } & \multicolumn{3}{|c|}{ Pseudo first order constants } & \multicolumn{3}{|c|}{ Pseudo second order constants } \\
\hline & $K_{1}\left(\min ^{-1}\right)$ & $q_{e}(\mathrm{mg} / \mathrm{g})$ & $\mathbf{R}^{2}$ & h $\left(g^{-1} g^{-1} \min ^{-1}\right)$ & $q_{e}(\mathrm{mg} / \mathrm{g})$ & $\mathbf{R}^{2}$ \\
\hline MSAC & 0.065 & 1.582 & 0.943 & 0.0333 & 0.002944 & 0.894 \\
\hline MS & 0.051 & 2.450 & 0.872 & 0.028377 & 0.003815 & 0.803 \\
\hline
\end{tabular}

of freedom within the groups was 8 for each adsorbent.

For MS, the $\mathrm{F}$ and $\mathrm{P}$ values implied a strong dependence of $\mathrm{C}_{\mathrm{e}}$ on the various parameters investigated $\left(\mathrm{C}_{\mathrm{A}}, \mathrm{M}, \mathrm{t}, \mathrm{T}, \mathrm{r}\right.$ and $\left.\mathrm{pH}\right)$. The Bonferroni-Holm Posthoc parametric significance test for various parameters investigated showed very strong dependence or significance on each other except for the relationship between $\mathrm{C}_{\mathrm{e}}$ and $\mathrm{M}$ with a $\mathrm{P}$ value of 0.198883 , which was greater than 0.05 in the $95 \%$ confidence interval.

This could be that the mass of adsorbent used to contact the adsorbate was too much than the relevant quantity needed, hence seems not to constitute a limiting factor in the adsorption process.

In the case for MSAC, the ANOVA and Bonferroni-Holm Posthoc significance test for crude oil adsorption with varying parameters as also given in Table 3 showed the actual values of the sum of squares within the groups and the sum of squares between the groups. There existed a statistically wide variation between the individually investigated parameters and the equilibrium concentration groups at the $95 \%$ confidence interval, as the $\mathrm{F}(1,8)$ and $\mathrm{P}$ values are mostly within expected ranges. Fisher's $\mathrm{F}$ is still the ratio of the variance between groups to the variance within groups and $\mathrm{P}$ is a probability factor that must be less than 0.05 in the ANOVA analysis. The degree of freedom between the groups was also 1 , while the degree of freedom within the groups was still 8. The $\mathrm{F}$ and $\mathrm{P}$ values implied a strong dependence of $\mathrm{C}_{\mathrm{e}}$ on the various parameters investigated $\left(\mathrm{C}_{\mathrm{A}}, \mathrm{M}, \mathrm{t}, \mathrm{T}, \mathrm{r}\right.$ and $\mathrm{pH}$.

The Bonferroni-Holm Posthoc parametric significance test for various parameters investigated showed very strong dependence or significance on each other except also for the relationship between $\mathrm{C}_{\mathrm{e}}$ and $\mathrm{M}$ with a $\mathrm{P}$ value of 0.537811 , which was greater than 0.05 in the $95 \%$ confidence interval. This could also be interpreted to mean that the mass of adsorbent used to contact the adsorbate was too much than the relevant quantity needed, hence seems not to constitute a limiting factor in the adsorption process.

\subsection{Kinetic Studies}

The pseudo first order kinetic model is given in Eq. (7) as:

$$
\log \left(q_{e}-q_{t}\right)=\log q_{e}-\left(K_{1} / 2.303\right) t
$$

The pseudo second order kinetic model is given in Eq. (8) as: 


$$
\frac{t}{q_{t}}=\frac{1}{h}+\frac{1}{q_{e} t}
$$

The constants from the plots of the pseudo first and second order kinetics are given in Table 4 . It can be seen that the pseudo first order kinetics gave a better fit for the two adsorbents with values of 0.943 and 0.872 for MSAC and MS, respectively.

\section{Conclusions}

The possibility of mango shell as a natural adsorbent to remove crude oil had been investigated in this work. The results demonstrated that crude oil removal by adsorption onto MS being a waste material is feasible. The adsorption and percentage removal of crude oil was found to be dependent at various levels on adsorbent dose, adsorbate dose, contact time, temperature and $\mathrm{pH}$ as well as speed of agitation. The adsorbed oil-water ratio of the mango adsorbent was more than unity in all cases investigated, which indicated higher adsorption selectivity for crude oil over water by the adsorbent. The considered adsorption temperature range was between 15 to $60^{\circ} \mathrm{C}$, with the maximum adsorption observed at $15^{\circ} \mathrm{C}$.

The correlation coefficient indicated various dependencies on parameters utilized by the adsorption process. Based on the high affinity for oil with low water pick up, MS used as an adsorbent could be expressly regarded as an oleophilic or hydrophobic substance. The equilibrium adsorption isotherm analysis with Langmuir, Freundlich, Temkin and Dubinin Raduskevich presented fitted the equilibrium data reasonably well, but Dubinin Raduskevich isotherm seems least significant because of the low $\mathrm{R}^{2}$ values. In conclusion, the result from the Temkin isotherm model seems to be the most significant, similar to the findings of Sidik et al. [34]. Optimum parametric values needed for the adsorption process were also presented. The results obtained with the Bonferroni-Holm Posthoc parametric significance test showed that the lowest $\mathrm{P}$ value for MS was 0.003261, while that for Mango shell activated carbon was 0.002991 under the same condition of variation of equilibrium concentration with mixing speed. The enhanced effect brought about by activation of the mango shell to provide an adsorbent with higher surface area and capacity for adsorption was therefore justified statistically using ANOVA and Bonferroni-Holm Posthoc significance test. The pseudo first order kinetics gave a better fit for the two adsorbents used for the adsorption operation.

\section{Acknowledgments}

The Chemical and Petroleum Engineering Department as well as the Central Research Laboratory of the University of Lagos, Akoka, Yaba, Lagos, Nigeria is appreciated for providing supporting services and useful advice during the experimental stage of this work.

\section{Nomenclature}

$A_{T} \quad$ Temkin Isotherm Equilibrium Binding Constant $\left(\mathrm{dm}^{3} / \mathrm{mol}\right)$
$\mathrm{B}_{\mathrm{D}} \quad$ Dubinin - Radushkevish isotherm energy parameter

$b_{T} \quad$ Temkin Isotherm Constant $(\mathrm{J} / \mathrm{mol})$

$C_{A} \quad$ Adsorbate Concentration, mg/L

$C_{e} \quad$ Equilibrium Concentration of Mixture (mg/L)

$\mathrm{C}_{0} \quad$ Initial Concentration of Mixture (mg/L)

$\mathrm{D}_{\mathrm{FB}} \quad$ Degrees of freedom between groups

$\mathrm{D}_{\mathrm{FW}}$ Degrees of freedom within groups

F Fisher's ratio

$\mathrm{h} \quad$ Pseudo second order constant $\left(\mathrm{gmg}^{-1} \mathrm{~min}^{-1}\right)$

$K_{1} \quad$ Pseudo First Order Constants (min- ${ }^{1}$ )

$K_{a d} \quad$ Dubinin-Radushkevich Isotherm Constant $\left(\mathrm{mol}^{2} / \mathrm{kJ}{ }^{2}\right)$

$K_{F} \quad$ Freundlich equilibrium constant which indicate adsorptive capacity

$K_{L} \quad$ Langmuir Constants $(\mathrm{mg} / \mathrm{g})$

$M, m$ Mass of the Adsorbent (g)

$n \quad$ Freundlich constant which indicate adsorptive capacity

$\mathrm{P}$ probability factor

$\mathrm{P}_{\mathrm{C}} \quad$ Critical probability factor

$\mathrm{pH} \quad$ Level of acidity or alkalinity

qD Dubinin-Radushkevich isotherm constant

$q_{e} \quad$ Amount of Solute Removed or Adsorbed at Equilibrium (mg/g)

$q_{m} \quad$ Theoretical Isotherm Saturation Capacity (mg/g)

$q_{s} \quad$ Theoretical Isotherm Saturation Capacity (mg/g)

$q_{t} \quad$ Amount of Solute Removed or Adsorbed at any time (mg/g)

$\mathrm{r} \quad$ Mixing speed, rpm

$\mathrm{R} \quad$ Universal Gas Constant (J/mol K)

$R^{2} \quad$ Coefficient of Regression

$\mathrm{S}_{\mathrm{SB}} \quad$ Sum of squares between groups

$\mathrm{S}_{\mathrm{SW}} \quad$ Sum of squares within groups

t Mixing time, min

$\mathrm{T}$ Temperature, $\mathrm{K}$

$V \quad$ Volume of Simulated Oil spill (L)

\section{References}

1. Lin J, Shang Y, Ding B, Yang J, Yu J, Al-Deyab SS. Nanoporous polystyrene fibers for oil spill cleanup. Mar. Pollut. Bull. 2011;20:1-6.

2. Annunciado TR, Sydenstricker THD, Amico SC. Experimental investigation of various vegetable fibers as sorbent materials for oil spills. Mar. Pollut. Bull. 2005;50:1340-1346.

3. Angelova D, Uzunov I, Uzunova S, Gigova A, Minchev L. Kinetics of oil and oil products adsorption by carbonized rice husks. Chem. Eng. J. 2011;172:306-311.

4. Ayotamuno MJ, Kogbara RB, Ogaji SOT, Probert SD. Bioremediation of a crude-oil polluted agricultural-soil at Port Harcourt, Nigeria. Appl. Energ. 2006;83:1249-1257.

5. Broder JM, Zeller TJ. Gulf oil spills are bad, but how bad? [Internet]. N.Y. Times; [cited 8 September 2016]. Available from: http://www.nytimes.com/2010/05/04/science/earth/04enviro.html.

6. Bhatnagar A, Sillanpaa M. Utilization of agro-industrial and municipal waste materials as potential adsorbents for water treatment - A review. Chem. Eng. J. 2010;157:2270-2296.

7. Mohammed AR, Lee KT, Noor NM, Zainuddin NF. Oil palm ash $/ \mathrm{Ca}(\mathrm{OH})_{2} / \mathrm{CaSO}_{4}$ adsorbent for flue gas desulfurization. 
Chem. Eng. Technol. 2005;28:939-945.

8. Saleh TA, Gupta VK. Photo-catalyzed degradation of hazardous dye methyl orange by use of a composite catalyst consisting of multi-walled carbon nanotubes and titanium dioxide. $J$. Colloid Interf. Sci. 2012;371:101-106.

9. Saleh TA, Gupta VK. Column with CNT/magnesium oxide composite for lead (II) removal from water. Environ. Sci. Pollut. Res. 2012;19:1224-1228.

10. Saleh TA. Isotherm, kinetic, and thermodynamic studies on $\mathrm{Hg}$ (II) adsorption from aqueous solution by silica-multiwall carbon nanotubes. Environ. Sci. Pollut. Res. 2015;22:1672116731.

11. Saleh TA. Nanocomposite of carbon nanotubes/silica nanoparticles and their use for adsorption of $\mathrm{Pb}$ (II): From surface properties to sorption mechanism. Desalin. Water Treat. 2016;57:10730-10744.

12. Saleh TA, Gupta VK. Processing methods, characteristics and adsorption behavior of tire derived carbons: A review. $A d v$. Colloid Interf. Sci. 2014;211:93-101.

13. Gupta VK, Kumar R, Nayak A, Saleh TA, Barakat MA. Adsorptive removal of dyes from aqueous solution onto carbon nanotubes: A review. Adv. Colloid Interf. Sci. 2013;193:24-34.

14. Saleh TA. Mercury sorption by silica/carbon nanotubes and silica/activated carbon: A comparison study. J. Water Supply Res. T. 2015;64:892-903.

15. Gupta VK, Ali I, Saleh TA, Nayak A, Agarwal S. Chemical treatment technologies for waste-water recycling - An overview. RSC Adv. 2012;2:6380-6388.

16. Saleh TA, Gupta VK. Synthesis and characterization of alumina nano-particles polyamide membrane with enhanced flux rejection performance. Sep. Purif. Technol. 2012;89:245-251.

17. Saleh TA, Tuzen M, Sarı A. Polyethylenimine modified activated carbon as novel magnetic adsorbent for the removal of uranium from aqueous solution. Chem. Eng. Res. Des. 2017;117:218-227.

18. Saleh TA, Sarı A, Tuzen M. Optimization of parameters with experimental design for the adsorption of mercury using polyethylenimine modified-activated carbon. J. Environ. Chem. Eng. 2017;5:1079-1088.

19. Saleh TA, Sarı A, Tuzen M. Effective adsorption of antimony (III) from aqueous solutions by polyamide-graphene composite as a novel adsorbent. Chem. Eng. J. 2017;307:230-238.

20. Haruna K, Saleh TA, Hossain MK, Al-Saadi AA. Hydroxylamine reduced silver colloid for naphthalene and phenanthrene detection using surface-enhanced Raman spectroscopy. Chem. Eng. J. 2016;304:141-148.
21. Saleh TA, Sarı A, Tuzen M. Chitosan-modified vermiculite for As (III) adsorption from aqueous solution: Equilibrium, thermodynamic and kinetic studies. J. Mol. Liq. 2016;219: 937-945

22. Gupta VK, Kumar R, Nayak A, Saleh TA, Barakat MA. Adsorptive removal of dyes from aqueous solution onto carbon nanotubes: A review. Adv. Colloid Interf. Sci. 2013;193:24-34.

23. Saleh TA. Mercury sorption by silica/carbon nanotubes and silica/activated carbon: a comparison study. J. Water Supply Res. T. 2015;64:892-903.

24. Mise SR, Jagannath SG. Adsorption studies of colour removal by activated carbon derived from Mangifera indica (mango) seed shell. Int. J. Res. Eng. Technol. 2013;2(S1):325-328.

25. Kwaghger A, Adejoh E. Optimization of conditions for the preparation of activated carbon from mango nuts using $\mathrm{ZnCl}_{2}$. Int J. Eng. Res. Dev. 2012;1:1-7.

26. Uzoije AP, Onunkwo A, Egwuonwu N. Crude oil sorption onto groundnut shell activated carbon: Kinetic and isotherm studies. Res. J. Environ. Earth Sci. 2011;3:555-563.

27. Coates J. Interpretation of infrared spectra, a practical approach. In: Meyers RA, ed. Encyclopedia of analytical chemistry. Chichester: John Wiley \& Sons Ltd.; 2000. p. 10815-10837.

28. Itodo AU, Itodo AH. Surface coverage and adsorption study of dye up take derived acid and base treated mango seed shell. J. Chem. Pharmaceut. Res. 2010;2:673-683.

29. Bello OS, Ahmad MA. Adsorptive removal of a synthetic textile dye using cocoa pod husks. Toxicol. Environ. Chem. J. 2011;93:1298-1308.

30. Lin CC, Liu HS. Adsorption in a centrifugal field: Basic dye adsorption by activated carbon. Ind. Eng. Chem. Res. 2000;39: 161-167.

31. Olufemi BA, Jimoda LA, Agbodike NF. Adsorption of crude oil using meshed concorbs. Asian J. Applied Sci. Eng. 2014;3: $7-21$

32. Agarry SE, Ogunleye OO, Aworanti AO. Biosorption equilibrium, kinetic and thermodynamic modeling of naphthalene removal from aqeous solution onto modified spent tea leaves. Environ. Technol. 2013;34:825-839.

33. Kumar GV, Ramalingam P, Kim MJ, Yoo CK, Kumar MD. Removal of acid dye (violet 54) and adsorption kinetics model of using musa spp. waste: A low-cost natural sorbent material. Korean J. Chem. Eng. 2010;27:1469-1475.

34. Sidik SM, Jalil AA, Triwahyono S, Adam SH, Satar MAH, Hameed BH. Modified oil palm leaves adsorbent with enhanced hydrophobicity for crude oil removal. Chem. Eng. J. 2012;203: 9-18. 